\title{
Exploration on Teaching Practice of Material Mechanics Course for the Run-through External Cultivation in Vocational College
}

\author{
Shang Wang ${ }^{1 *}$, Jinru Ma ${ }^{1}$, Huagang Liu ${ }^{1}$, Zhixin Feng ${ }^{1}$ \\ ${ }^{1}$ School of Automotive Engineering, Beijing Polytechnic, Beijing 100176, China \\ "Corresponding author. Email: wangshang @bpi.edu.cn
}

\begin{abstract}
The paper expounds the construction background of the run-through external cultivation, and analyzes the common problems in the teaching of material mechanics in traditional vocational colleges. Combined with the curriculum characteristics of Conestoga College, a connecting school for the class of run-through external cultivation, this paper puts forward the teaching methods of "Pre-class Suspense" (PCS), and has achieved good results in teaching practice. The results show that the setting of PCS can obviously enhance students' interest in learning, activate class atmosphere, and improve the effect of listening to class. The PCS teaching method should be applied in more teaching courses.
\end{abstract}

Keywords: Vocational Colleges, Run-through External Cultivation, Material Mechanics.

\section{BACKGROUND INTRODUCTION}

In order to adapt to the needs of economic and social development of the capital, higher vocational colleges are constantly reforming. At present, China is in the period of industrial transformation, so it is necessary to explore the new mode and new path of training high-end technical and skilled personnel. Under such a background, the Beijing municipal government launched a major reform project of higher vocational education in 2015: " $2+3+2$ " advanced technical and skilled talents run-through experimental cultivation project (referred to as the " $2+3+2$ "). In the " $2+3+2$ " experimental project, the first " 2 " refers to the first two years of basic cultural education, the middle " 3 " refers to the three years of professional courses and vocational skills education, and the last " 2 " refers to the completion of undergraduate learning tasks in the last two years and obtained a bachelor's degree [1-3].

Based on the " $2+3+2$ " experimental project, national model school for higher vocational education, Beijing Polytechnic, joint United States, Germany, Canada, France, Britain and other foreign university of applied technology, actively explore and promote the international run-through external cultivation system, it is different from traditional " $2+3+2$ " experimental project, the main characteristics is, the last " 2 " refers to students complete their undergraduate studies at universities abroad in the last two years. Students who take part in the internationalized run-through external cultivation (hereinafter referred to as "run-through external cultivation") are required to choose a foreign major language and minor language according to the requirements of foreign universities after enrollment, and the learning of professional courses is based on the foreign language textbooks and syllabus designated by the universities, in order to adapt to the further study abroad [4].

Obviously, the traditional teaching mode, teaching content and teaching method are difficult to adapt to the requirements of the run-through external cultivation, especially in the most critical three-year professional courses and vocational skills education stage. How to explore a teaching mode that can meet the requirements of foreign universities of applied technology and realize the seamless connection between domestic and foreign education, so as to draw on the strengths of domestic and foreign education and cultivate international highend technical and skilled talents with broad vision and strong quality? This is a problem worthy of deep research and exploration in vocational colleges.

The class of mechanical and electrical engineering (2016) is the second class of run-through external 
cultivation in Beijing Polytechnic. The class is connected with a foreign university, Conestoga College in Canada. The author undertook the teaching of material mechanics course of this class, and made some relevant reform and practice in teaching content and teaching methods, and achieved good teaching results. The logical framework of this paper is shown in Fig. 1.

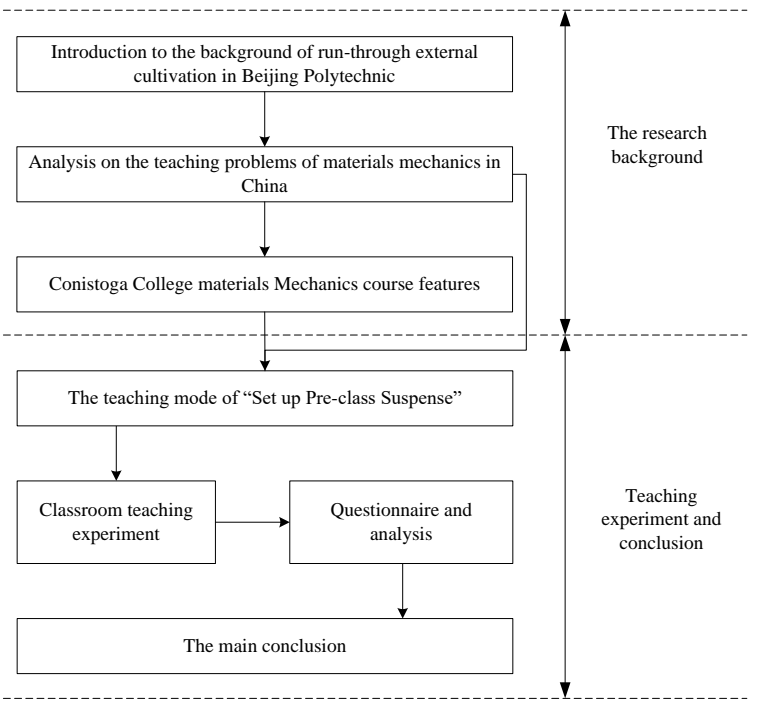

Figure 1 The logical framework of the paper

\section{TEACHING PROBLEM OF MATERIAL MECHANICS COURSE}

Mechanics of materials is a compulsory course for engineering majors such as machinery, automobile and rail transit, and it is also an important basic professional course. The learning effect will directly affect the subsequent professional courses, such as Fundamentals of Mechanical Design, Metal Cutting, Automobile Structure and Automobile Manufacturing Technology, etc. [5]. In the teaching of higher vocational colleges, this course mainly faces the following problems:

\subsection{The Teaching Content Is Broad And Theoretical}

At present, the material mechanics teaching content of domestic higher vocational colleges are mostly inherited from undergraduate colleges, and the teaching content is too broad, theoretical, and lack of vocational teaching characteristics. The traditional teaching system is convenient for students to grasp the basic concepts and formulas, but too much emphasis is placed on the systemic of knowledge and structural integrity, which inevitably leads to too much teaching content, and students generally feel heavy academic pressure. The teachers spend a lot of time explaining the knowledge of statics and dynamics in class, especially the derivation process of complex formulas such as moment of inertia and polar moment of inertia based on mathematical calculus knowledge, the content and conception is empty and difficult, higher vocational college students is hard to accept. Even if the students can understand the teaching content, they can not use it skillfully [6].

\subsection{The Teaching Process Is Boring And Can Not Arouse Students' Interest}

Mechanics of materials is a subject with strong application. In the process of teaching implementation, we should not only pay attention to the teaching of students' theoretical knowledge, but also train students' ability to solve practical engineering problems. There are many concepts and formulas of this course, and the teaching content is abstract. Besides, the students lack of the actual production and life experience, so they generally feel dull, boring and cannot understand the teaching content, which seriously affects their initiative and enthusiasm in learning. The actual teaching situation of material mechanics in higher vocational colleges is that teachers are struggling to teach, students are also struggling to learn, and the teaching effect is very bad.

\subsection{The Examples And Exercises In The Textbook Are Stereotypical And Lack Of The Connection With Engineering Practice}

The examples and exercises in material mechanics textbooks of higher vocational colleges are too stereotypical. Most of them set corresponding questions by slightly deforming the formulas and conclusions in the teaching content, which have little connection with the practical engineering problems. For vocational colleges aiming at cultivating application-oriented talents, the purpose of learning mechanics of materials is mainly to master the basic methods of force analysis of various mechanical structures, and to focus on cultivating the ability to solve practical problems[7-9]. This also affects the interest of students mentioned above.

\section{CHARACTERISTICS OF COURSES IN THE CONESTOGA COLLEGE}

Conestoga College, which connects the run-through external cultivation, provides the syllabus, task lists, reference assignments and examination papers for all specialized courses teaching implementation. Through many academic exchanges and study of relevant teaching materials, the author sorts out the main characteristics of material mechanics teaching in Conestoga College:

(1) Students only need to do a preliminary understanding "how to derive this formula". Conestoga College's courses focus on using formulas to solve 
practical problems. For example, a new formula, where can it be used? How do students use it?

(2) Attach importance to the comprehensive application of knowledge and analyze problems in multiple dimensions. For example, domestic material mechanics courses are all about mechanical characteristics under normal temperature environment. But Conestoga College's mechanical analysis takes into account changes in the surrounding environment.

(3) Diversified evaluation mode and pay attention to the usual homework results. In terms of the evaluation methods, Conestoga College focuses on the usual course assessment, in which the major assignments account for $20 \%$, the lab reports account for $20 \%$, the mid-term exam accounts for $30 \%$, and the final exam only accounts for $30 \%$, as shown in Table 1 .

Table 1. Teaching tasks and percentage of the total score

\begin{tabular}{|l|l|l|}
\hline Teaching tasks & Quantity & Percentage \\
\hline Assignments-Problem Based & 5 & $20 \%$ \\
\hline Lab Reports & 4 & $20 \%$ \\
\hline Mid-Term Exam & 1 & $30 \%$ \\
\hline Final Exam & 1 & $30 \%$ \\
\hline
\end{tabular}

\section{TEACHING PRACTICE}

In view of the problems existing in the teaching of material mechanics courses in higher vocational colleges, combined with the teaching characteristics and requirements of Conestoga College, the teaching mode of PCS was set and the teaching practice was carried out. The test class was the mechanical and electrical engineering(2016) of run-through external cultivation.

Before explaining the abstract and difficult theoretical knowledge, the author set up PCS in the class of the material mechanics course, in order to stimulate students' interest and motivation in learning.

\subsection{Execution Process Of PCS}

The implementation of PCS programmes is planned. Before classroom teaching, the author has done a lot of preparatory work to ensure the efficiency of teaching. The PCS execution process is shown in Fig. 2.

The PCS application consists of the following steps:

(1) Summarize the main points of knowledge taught in class.

(2) Summarize the original students' wrong understanding of this knowledge point.

(3) Sum up the original students' paper mistakes.
(4) Analyze the application of this knowledge point in daily life.

(5) PCS was set up in combination with (1) to (4) above.

(6) The application of PCS.

(7) PCS feedback and improvement.

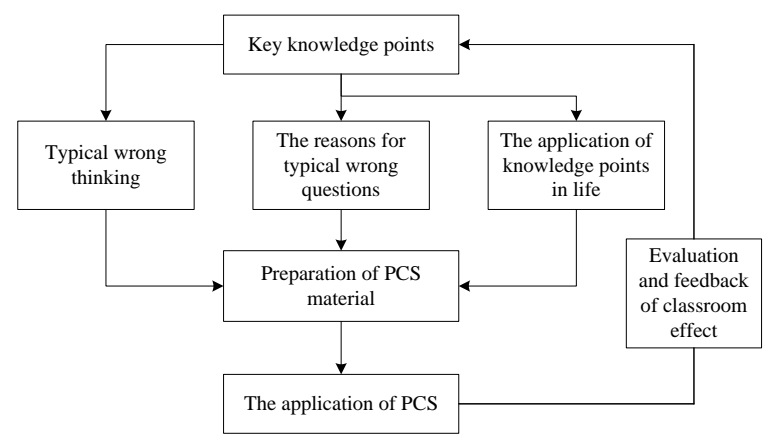

Figure 2 Execution process of PCS



Figure 3 Scaffolding used on a construction site

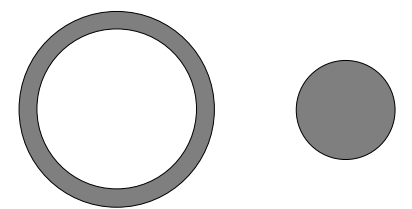

Figure 4 Different cross section shapes of scaffolding

\subsection{Application Of PCS}

This paper expounds the specific application and teaching effect of PCS through specific cases. In order to explain the load capacity of hollow circular shaft and solid circular shaft with equal cross-sectional area, the author introduced the case of scaffolds (as shown in Fig. 3 ), and the question was: why are the scaffolds hollow rather than solid?

The students gave the answer quickly: because it saves material. Subsequently, the author raised another question: if you are right, why not make it cylindrical (with a smaller diameter) as shown in Fig. 3 (on the right side)? After all, hollow pipe processing is more complicated. The students soon realized that the beginning answer had been premature. Then, they became interested in discussing the question: why the scaffolds were hollow and began to figure it out. The 
author then remarked that the answer to the question was in this class teaching content. To solve this puzzle, it is necessary to understand the concept of polar moment of inertia and moment of inertia in the book. The polar moment of inertia Ip (as shown in Formula 1), represents an object's ability to resist torsion [10-11]. The moment of inertia Iz (as shown in Formula 2), reflects an object's ability to resist bending. If it is a solid axis, the value of $\mathrm{d}$ in Formula 1 is 0 , so is Formula 2. Further, the author and students analyzed the values of Ip and Iz through a typical example. Through the data calculation of this problem, the students found the following conclusion:

In the case of the same cross-sectional area (that is, the same amount of material used), the Ip value and Iz value of the hollow shaft is much larger than that of the solid shaft. In the end, the students found that the torsion and bending resistance of hollow scaffolds were much higher than those of solid scaffolds without additional materials. In this way, students will subconsciously feel that the mechanics is not esoteric, not abstract, just around us, and it is closely related to the real life.

$\mathrm{I}_{\mathrm{p}}=\frac{\pi \mathrm{D}^{4}}{32}\left(1-\frac{\mathrm{d}^{4}}{\mathrm{D}^{4}}\right)$

$\mathrm{I}_{\mathrm{z}}=\frac{\pi \mathrm{D}^{4}}{64}\left(1-\frac{\mathrm{d}^{4}}{\mathrm{D}^{4}}\right)$

\subsection{Results}

The application effect of PCS was investigated by questionnaire. Fifty students participated in the questionnaire, and each student had two votes. The voting options were:

Q1: PCS can arouse my interest in learning.

Q2: PCS can effectively reduce the difficulty of knowledge points.

Q3 : PCS enables me to have a deeper understanding of mechanical formulas.

Q4: PCS can reduce my fear of material mechanics.

Q5 : PCS can help me understand more about mechanics in life.

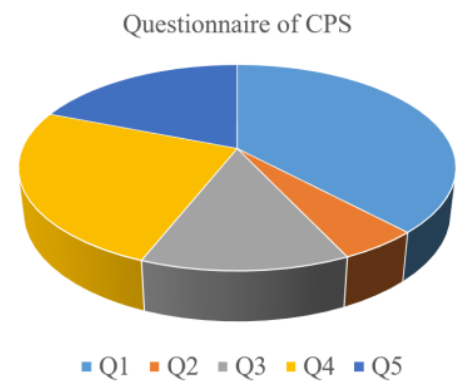

Figure 5 Students' questionnaire of PCS

A total of 100 questionnaires were collected and the data were statistically analyzed. The statistical results are shown in Fig. 5. As can be seen from Fig. 5, the greatest effect of PCT is to improve students' interest in learning $(38 \%)$. Reducing the fear of studying came in second $(25 \%)$, and strengthening the understanding of life mechanics ranked third (19\%). Deep understanding of formulas ranks fourth (13\%). Surprisingly, making learning less difficult came in last $(5 \%)$.

\section{CONCLUSION}

Through the PCS application in the classroom, the students' interest and motivation in learning were greatly improved, the classroom atmosphere was very active, and the effect of listening to the class was significantly improved. After raising questions, set aside a certain amount of time in class to allow students to speak and ask questions freely, encourage mutual communication, and promote students to think independently and analyze deeply. However, PCS cannot reduce the difficulty of material mechanics knowledge points, because the teaching content and difficulty of the course are regulated by the teaching syllabus. At present, there are still many problems in the teaching of material mechanics in vocational colleges, such as students lack of interest, lack of concentration, can not use what they have learned to solve practical problems and so on. Teachers should constantly explore and reflect from the perspective of students, and try new teaching methods, so as to make contributions to the new teaching reform of material mechanics.

\section{AUTHORS' CONTRIBUTIONS}

Jinru Ma did the questionnaire survey and data collation.

Shang Wang contributed significantly to analysis and manuscript preparation.

Huagang Liu and Zhixin Feng helped perform the analysis with constructive discussions.

\section{ACKNOWLEDGMENTS}

This paper was supported by the Project of Beijing Education Science Planning Project (NO. CCDB2020135 and NO. CGDB21208).

\section{REFERENCES}

[1] Chao, Y G.: An exploratory study on PE teaching in senior high school in the pilot project of comprehensive training of high-end technical and skilled personnel. Chinese Vocational and Technical Education 25, 69-72 (2017). 
[2] Chen, G.: Exploration on the theoretical basis of comprehensive training of high-end technical and technical talents -- taking Beijing as an example. Chinese Vocational and Technical Education 36, 83-87 (2018).

[3] Feng, L J.: Thinking and practice of " $2+3+2 "$ comprehensive training of high-end technical talents. Higher Education Development Study 09, 21-23 (2015).

[4] Feng, Y J.: Beijing Polytechnic has carried out comprehensive training for high-end technical and skilled personnel. Vocational and Technical Education 38(20), 6-6 (2017).

[5] Na, Z L, Ming Y Y.: Problems and improvement measures in mechanics teaching in higher vocational colleges. Theacher, 000(014), 71-72 (2016).

[6] Sheng, S D.: Problems and improvement measures in mechanics teaching in higher vocational colleges. New Curriculum Research 000(011), 105106 (2014).

[7] $\mathrm{Hu}, \mathrm{C} \mathrm{H} .:$ Research on the reform and development of the link between theory and practical engineering of material mechanics course teaching content. Value Engineering 01, 245-246 (2014).

[8] Chuan, X Y.: Reform of the connection between theory and practical engineering of material mechanics teaching content. Divineland 000(032), 145-145 (2014).

[9] Oda M, Iwashita K. Mechanics of Granular Materials: An Introduction (2020).

[10] Bedford A , Liechti K M. Mechanics of Materials (2020).

[11] Besson J, Cailletaud G. Non-Linear Mechanics of Materials. Springer Netherlands (2020). 